\title{
Sosialisasi Algoritma Basic Life Support AHA 2017 Bagi Masyarakat Awam
}

\author{
Sunarto, Sunarto ${ }^{1 *}$, Addi Mardi Harnanto ${ }^{2}$ \\ ${ }^{1,2}$ Jurusan Keperawatan, Politeknik Kesehatan Surakarta \\ *Email: sunarto_sst@yahoo.com
}

\begin{abstract}
Background: Recent developments both in terms of science, population density, modern lifestyle, increased activity, congestion in terms of transportation and so on have a real impact on life in society. One impact that is not recognized is less concerned about the risks of these developments. Where this makes individuals vulnerable to a disease and other threats. One of them is a heart attack, the number of accidents has increased, so there is a risk of trauma, even resulting in cardiac arrest and stopping breathing. In line with this, first aid in emergency conditions really needs to be known by all people. So we need a guide for the flow of help, which is currently with algoritma basic life support AHA 2017. Community service goals: The community understands the flow or algorithm of first aid for people with cardiac arrest and respiratory arrest. Methods: In the implementation using question and answer lecture and demonstration models, with the module learning media. Pre-test and post-test is done by asking questions. Results: There is a difference in the results of the correct answer before and after the socialization of the AHA 2017 basic life support algorithm. The increase is between 3 and 6. Conclusion: After socialization of basic life support algorithm AHA 2017 knowledge increased.
\end{abstract}

Keywords: algorithm, basic life support aha 2017, ordinary people, socialization

\section{PENDAhUluan}

Perkembangan terkini baik dari segi keilmuan, kepadatan penduduk, gaya hidup ke arah modern, kesibukan meningkat, kemacetan dari sisi transportasi dan sebagainnya mempunyai dampak yang nyata bagi kehidupan di masyarakat. Satu dampak yang tidak disadari adalah kurang peduli terhadap resiko perkembangan tersebut. Dimana hal tersebut menjadikan individu rentan terhadap suatu penyakit dan ancaman yang lain. Salah satunya serangan jantung, angka kecelakaan mengalami peningkatan, Faktor lainnya adalah disebabkan gaya hidup yang tidak sehat, sehingga, pilihan gaya hidup yang tidak sehat memainkan peranan yang besar. (Ulfa, 2019).

Kematian akibat serangan jantung dapat menyerang siapa saja, kapan saja, dimana saja, tetapi kejadian tersebut sangat mungkin pada seseorang yang rentan dengan sumber penyebab baik langsung maupun tidak langsung. Individu yang terpapar resiko dimungkinkan karena diawali gaya hidup yang kurang baik, lingkungan yang kurang kondusif, keramaian lalu lintas atau karena dampak penyakit penyerta. Dalam kondisi ini individu yang mengalami dapat terjadi serangan yang tiba-tiba dan hal tersebut terjadi di masyarakat awam. Sebenarnya kematian terhadap penderita serangan jantung bisa dihindari ketika penderita langsung mendapatkan penanganan awal. Sering kali terlambatnya pertolongan pertama kepada korban serangan jantung di tempat dan teknik pemberian pertolongan yang tidak tepat memicu kematian. (Indo HCF, 2016)

Seiring dengan perkembangan jaman bahwa pertolongan pertama pada kondisi kegawatan jantung sudah sangat lengkap dan terstruktur walaupun angka 
keberhasilannya sangat di pengaruhi berbagai faktor, salah satunya individu yang melakukannya. Dimana saat ini lagi tren menggunakan pedoman American Heart Association (AHA). (Monica E. Kleinman, et all. , 2017).

Pada tahun 2010 American Heart Association (AHA) telah mengeluarkan panduan dengan istilah cardiopulmonary resuscitation $(C P R)$ guidelines kemudian dilakukan perbaikan pada tahun 2015. Seiring perkembangan waktu terus dilakukan monitoring dan evaluasi secara utuh dan berkesinambungan yang tentunya disesuaikan dengan kemajuan ilmiah yang sedang berjalan dan tetap mengedepankan pada dampak terbesar pada kelangsungan hidup. Berdasarkan evidence based, AHA telah mengembangkan rekomendasi yang hasilnya telah dipublikasikan. Rekomendasi American Heart Association (AHA) 2015 merupakan penyempurnaan dari rekomendasi yang terdahulu. Dimana saat ini sudah ada perkembangan lagi untuk penyempurnaan yaitu AHA 2017. (Monica E. Kleinman, et all. , 2017).

Ditahun 2017 American Heart Association (AHA) menyempurnakan lagi, terkait dengan Cardio Pulmonary Resuscitation (CPR) Guidelines. Hal tersebut merupakan penyempurnaan yang mencakup CPR yang didampingi operator, pemberian kompresi dada dan pemberian kompresi dada dengan tangan saja.

Berdasarkan data yang tercantum diatas, hendaknya masyarakat umum mengerti alur atau algoritmanya sehingga mampu memberikan pertolongan pertama ketika berhadapan dengan kasus tersebut. Masyarakat kecamatan Ngemplak, Boyolali memiliki berbagai macam latar belakang, sehingga di mungkinkan memiliki pengetahuan khususnya algoritma basic life support (BLS) AHA 2017 belum pernah dilakukan. Memahami algoritma basic life support (BLS) AHA 2017 sebaiknya dapat dimiliki oleh masyarakat awam, karena masyarakat awam sering sebagai orang yang melihat pertama kali terhadap kejadian kasus-kasus yang sering terjadi di masyarakat, sehingga jika masyarakat awam perlu dibekali pengetahuan dan keterampilan melakukan pertolongan pertama diharapkan mereka akan memiliki kemampuan dalam pertolongan pertama, dan jika menjumpai kasus terkait di masyarakat mereka mampu memberikan pertolongan secara cepat dan tepat.

Dari uraian diatas, betapa pentingnya meningkatkan pengetahuan algoritma basic life support (BLS) AHA 2017 melalui pendidikan kesehatan dalam bentuk sosialisasi bagi warga di kecamatan ngemplak boyolali.

\section{TINJAUAN PUSTAKA}

\subsection{Konsep Dasar CPR Guidelines AHA 2017}

\subsubsection{Gambaran Umum}

Pedoman Cardio Pulmonary Resucitation (CPR) dan Perawatan Darurat Kardiovaskular telah dimuat pada Jurnal Circulation yang diterbitkan 2 November 2017. Dimana telah dilakukannya penelitian secara terus-menerus terkait CPR dan dilakukan berkesinambungan dalam 5 tahuan. (Yunanto, 2012). 
Model penyempurnaan berdasar evaluasi telah dilakukan secara lengkap mulai dari tahapan-tahapan CPR serta berdasar kemajuan ilmiah dan tetap memperhatikan pada kelangsungan hidup yang merupakan tujuan utama. Berdasar bukti evidance base yang kuat telah di terbitkan rekomendasi yang hasilnya lebih baik (Yunanto, 2012).

Pada pedoman AHA 2017 telah dikonfirmasi keamanan dan efektivitas dengan berbagai pendekatan, mulai dari ketidakefektifan, perkenalan dengan perawatan baru yang beorientasi bukti dan dan konsensus pakar. Dengan hadirnya rekomendasi baru merupakan penyempurnaan dari yang sebelumnya (Yunanto, 2012).

\subsubsection{Pedoman Resusitasi Jantung Paru}

Hal utama CPR 2017 bertumpu pada model naik turunnya dada. Dibawah ini pedoman secara umum untuk CPR 2017:

a. Menerapkan Model Awal dengan CAB

Pada rekomendasi AHA 2017 di ungkapkan untuk memprioritas circulation (C) dahulu baru diikuti dengan tindakan airway (A) kemudian breathing (B). Hal pengecualian khusus untuk bayi baru lahir (neonatus), tetap pada pola $\mathrm{ABC}$ dikarenakan kemungkinan terjadinya masalah jalan lahir (asfiksia) sebagai penyebab utama. Hal ini berlaku untuk RJP pada bayi, anak, ataupun orang dewasa yang umumnya karena sebab circulation (C) kecuali penolong melihat sendiri bahwa korban tidak sadarkan diri karena masalah lain

b. Fokus pada Mendengarkan dan Merasakan

Rekomendasinya ketika penolong melihat korban telah terjadi henti jantung maka segera melakukan tindakan bukan menilai dulu. Dengan segera meminta pertolongan dengan menghubungi mobil ambulance ketika melihat korban tidak sadar dan tidak bernafas dengan baik (gasping).

c. Tidak ada Tindakan Pemberian Nafas Buatan

Hal tersebut dihilangkan karena tindakan pemberian napas buatan sebanyak dua kali mengakibatkan waktu untuk pemberian kompresi dada tertunda.

d. Pijat Dada Lebih Dalam

Anjuran terbaru dalam melakukan pijat dada (kompresi) dengan kedalaman minimal 2 inchi $(5 \mathrm{~cm})$.

e. Frekuensi Pijat Dada Lebih Cepat

Anjuran yang terkini adalah kecepatan pijat dada (kompresi) minimal 100 kompresi/ menit. Dengan kata lain membutuhkan waktu yang lebih cepat.

f. Hanya dengan Tangan untuk $C P R$

Anjuran tersebut artinya pertolongan diutamakan dengan menggunakan tangan saja mengandung maksud fokus pada pijat dada (kompresi) tidak kombinasi dengan yang lain. 
g. Memfungsikan Emergency Response System (ERS)

Fokus dari hal ini adalah meminta pertolongan orang di sekitar, menelepon ambulans, ataupun menyuruh orang untuk memanggil bantuan dengan catatan seiring dengan melakukan pemeriksaan pada penderita.

h. Pijat Dada (Kompresi) Berkelanjutan

Maksud dari hal tersebut adalah agar aliran darah ke otak lancar sehingga kematian jaringan otak bisa dihindari. Harapannya hal ini dapat dilakukan sampai alat defibrilator otomatis datang untuk tindakan lebih lanjut. Bila memungkinkan pernapasan dari mulut ke mulut segera dilakukan seiring dengan kompresi dada. Utamanya Push Hard, Push Fast, Allow complete chest recoil, and Minimize Interruption tetap ada.

i. Tidak dianjurkan lagi Cricoid Pressure

Anjuran tersebut guna menghindari kesulitan pemasangan jalan nafas yang lebih adekuat serta aspirasi tetap dapat terjadi. Tindakan tersebut intinya adalah penekanan tulang rawan krikoid yang dilakukan pada korban dengan tingkat kesadaran sangat rendah.

j. Penggunaan Precordial Thump

Tindakan precordial thump diharapkan dapat mengembalikan irama ventricular tachyarrhytmias ke irama sinus. Perlu adanya resiko yang dapat ditimbulkan dari tindakan tersebut antara lain : fraktur sternum, osteomyelitis, stroke, dan bahkan bisa mencetuskan aritmia yang ganas pada korban dewasa dan anak-anak. Pertimbangan lain pada pasien dengan VT yang disaksikan, dapat di monitor, tidak stabil, dan defibrilator belum siap. Namun demikian RJP tetap harus berjalan.

\section{METODE}

\subsection{Tempat dan Waktu}

Tempat pelaksanaan wilayah Gagaksipat Ngemplak Boyolali pada bulan Januari-Juni 2019.

\subsection{Metode Pendekatan}

Tahapan dalam Pengabdian kepada masyarakat ini antara lain:

a. Tahap Awal

Penulis menyiapkan dengan menyusun proposal, penyusunan modul, mengurus perijinan dari pemangku kepentingan, penjajagan, dan melakukan koordinasi dengan pihak Desa Gagaksipat Kecamatan Ngemplak Boyolali.

b. Tahap Pelaksanaan

Pada pelaksanaan pengabdian kepada masyarakat ini dengan memberikan pendidikan pada warga Gagaksipat Ngemplak Boyolali. Dengan media pembelajaran modul. Sebelumnya diawali pretest dengan memberikan pertanyaan secara langsung dalam bentuk kuis berjumlah 10 pertanyaan dan warga diberikan lembar jawaban. 
c. Tahap Evaluasi

Evaluasi kegiatan pendidikan kesehatan dilakukan dengan melakukan post test dengan memberikan pertanyaan secara langsung dalam bentuk kuis berjumlah 10 pertanyaan dan warga diberikan lembar jawaban.

d. Tahap Penyusunan Laporan Kegiatan

Pada tahap ini yang dilakukan adalah diskusi, menyusun konsep laporan, pembahasan dan membuat laporan akhir pengabdian kepada masyarakat.

\subsection{Personalia}

Kegiatan pengabmas ini dilakukan dengan tim terdiri dari dua orang dengan sasaran adalah warga Gagaksipat Ngemplak Boyolali

\subsection{Jadwal Kegiatan}

Tabel 1. Kalender Pelaksanaan Kegiatan Pengabdian Masyarakat

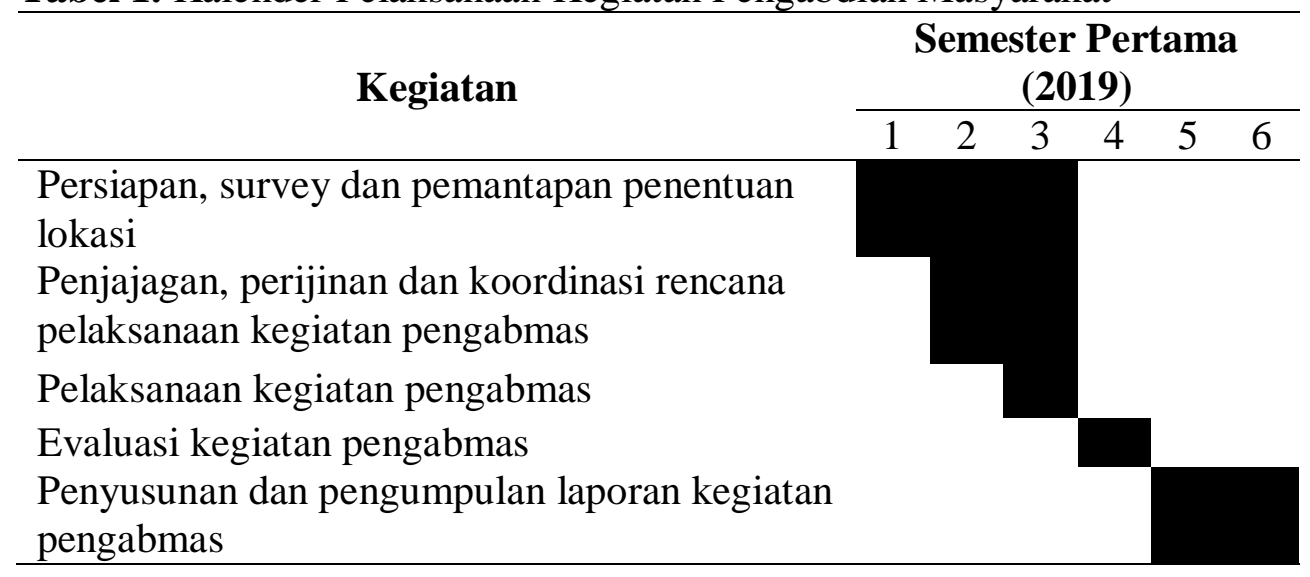

\section{HASIL}

\subsection{Pelaksanaan Kegiatan}

a. Persiapan

1) Membuat makalah dan modul untuk kegiatan

2) Survey dan pemantapan penentuan lokasi

Melakukan pendekatan dan mencari data awal permasalahan yang perlu mendapatkan penanganan rentang januari - maret 2019

3) Penjajagan serta koordinasi awal dengan pemangku kepentingan Gagaksipat Ngemplak Boyolali hari minggu 17 Maret 2019, kemudian ditentukan koordinasi persiapan minggu 24 Maret 2019

b. Pelaksanaan

Pelaksanaan kegiatan hari minggu 31 Maret 2019

c. Evaluasi hasil

Evaluasi dilakukan pada hari Minggu 14 April 2019 


\subsection{Hasil Pelaksanaan Pendidikan Kesehatan}

Berdasarkan hasil pengamatan langsung dan memberikan pertanyaan secara langsung dalam bentuk kuis, hasil sebagai berikut :

a. Pengetahuan dan pemahaman meningkat

b. Meningkatnya hasil evaluasi pada sebelum dan sesudah kegiatan, tabel dibawah menunjukan perubahan terhadap pendidikan kesehatan.

Tabel 2. Jawaban Benar Sebelum dan Sesudah dilakukan Pendidikan Kesehatan

\begin{tabular}{|c|c|c|c|}
\hline \multirow{2}{*}{ Kode Peserta } & \multicolumn{2}{|c|}{ Jawaban Benar } & \multirow{2}{*}{ Keterangan } \\
\hline & Pre & Post & \\
\hline 1 & 1 & 5 & Naik \\
\hline 2 & 1 & 5 & Naik \\
\hline 3 & 3 & 6 & Naik \\
\hline 4 & 2 & 5 & Naik \\
\hline 5 & 3 & 7 & Naik \\
\hline 6 & 3 & 6 & Naik \\
\hline 7 & 2 & 6 & Naik \\
\hline 8 & 3 & 7 & Naik \\
\hline 9 & 4 & 8 & Naik \\
\hline 10 & 3 & 7 & Naik \\
\hline 11 & 2 & 5 & Naik \\
\hline 12 & 3 & 7 & Naik \\
\hline 13 & 2 & 6 & Naik \\
\hline 14 & 1 & 6 & Naik \\
\hline 15 & 1 & 6 & Naik \\
\hline 16 & 1 & 7 & Naik \\
\hline 17 & 1 & 6 & Naik \\
\hline 18 & 2 & 7 & Naik \\
\hline 19 & 3 & 5 & Naik \\
\hline 20 & 2 & 5 & Naik \\
\hline 21 & 1 & 5 & Naik \\
\hline 22 & 4 & 6 & Naik \\
\hline 23 & 2 & 5 & Naik \\
\hline 24 & 2 & 5 & Naik \\
\hline 25 & 2 & 7 & Naik \\
\hline 26 & 2 & 5 & Naik \\
\hline 27 & 3 & 6 & Naik \\
\hline 28 & 4 & 7 & Naik \\
\hline 29 & 4 & 7 & Naik \\
\hline 30 & 4 & 8 & Naik \\
\hline 31 & 3 & 8 & Naik \\
\hline
\end{tabular}




\subsection{Faktor yang Mendukung dan yang Menghambat}

Hal yang mendukung dari masyarakat adalah adanya kemauan masyarakat untuk ingin tahunya cukup besar dan kedisiplinan dari waktu. Sedangkan faktor yang menjadikan penghambat adalah latar belakang dan paparan informasi yang tidak merata sehingga cukup berpengaruh pada model penyampaian.

\section{PEMBAHASAN}

Setelah memperhatikan pada tabel 2 dapat memberikan gambaran adanya peningkatan jumlah jawaban benar antara sebelum dan sesudah diberikan sosialisasi terkait algoritma BLS AHA 2017. Rentang kenaikan antara 3 sampai dengan 6. Berdasarkan hal tersebut dapat disimpulkan bahwa pengetahuan dan pemahaman warga tentang algoritma BLS AHA 2017 telah terjadi peningkatan. Sebagai dasar penguat dari hal tersebut adalah teori yang ungkapkan oleh Notoatmojo pada tahun 2007 yang intinya pengetahuan merupakan hasil dari tahu yang terjadi setelah melakukan penginderaan terhadap suatu objek tertentu. Sedangkan cakupannya meliputi semua panca indera manusia. Dimana tindakan yang di lakukan merupakan domain dari suatu pengetahuan. Agar perilaku menjadi langggeng maka perlu dasar pengetahuan, kesadaran dan sikap positif, begitu sebaliknya. Ungkapan lainnya bahwa pengetahuan berhubungan erat dengan pendidikan, media dan keterpaparan informasi ( Meliono, 2007).

Notoatmodjo (2007) memberikan gambaran pengetahuan mulai dari tahu (know), memahami (compression), aplikasi (application), analisis (analysis), sintesis (synthesis), evaluasi (evaluation). Berpijak dari teori tersebut penulis artikan upaya pendidikan kesehatan yang telah kami laksanakan masih pada tahap memahami (compression). Hal tersebut di mungkinkan karena baru pertama terpapar tentang sosialisasi algoritma BLS AHA 2017 dengan waktu yang singkat.

Hal yang lain yang juga mempengaruhi adalah karakteristik dari lingkungan sekitar, dimana adanya latar belakang yang beraneka ragam, misal pendidikan setiap individu yang mengikuti sosialisasi, dengan hasil diskusi riil didapatkan yang cukup berbagai tingkatan pendidikan, mulai dari SD sampai dengan perguruan tinggi. Yang tentunya hal tersebut mempunyai kaitannya dengan cara pandang, maupun daya terima dari setiap individu. ( Meliono, 2007)

\section{KESIMPULAN DAN SARAN}

\subsection{KESIMPULAN}

Simpulan dari kegiatan ini adalah dengan sosialisasi algoritma BLS AHA 2017 dapat meningkatkan pengetahuan dan pemahaman warga tentang alur pertolongan pertama pada kegawatdaruratan khususnya henti jantung dan henti nafas. 


\subsection{SARAN}

Saran yang perlu ditindaklanjuti antar lain mengagendakan kegiatan selanjutnya dalam bentuk skill secara riil, perlu kegiatan secara berkesinambungan serta melibatkan lebih banyak peserta dan mendorong kader kesehatan didesa lebih aktif dalam kegiatan ini.

\section{UCAPAN TERIMA KASIH}

Dengan terlaksanannya kegiatan pengabmas ini dengan baik kami haturkan banyak terimakasih Satino, SKM., MSc. selaku Direktur Politeknik Kesehatan Kemenkes Surakarta, Widodo, MN. Selaku Ketua Jurusan Keperawatan Politeknik Kesehatan Kemenkes Surakarta, Yuyun Setyorini,SKp,Ns.,MKep, selaku Kepala Unit Pengabdian Masyarakat Politeknik Kesehatan Kemenkes Surakarta. Kepala Desa dan Ketua RT 6 RW 6 Desa gagaksipat, Ngemplak Boyolali

\section{DAFTAR RUJUKAN}

Goswami, S., Kanika, and Sembian, N. (2015). Effectiveness Of Training Program On Knowledge and Practices Regarding Basic Life Support (BLS) Among Nursing Students. Int J Clin Anesthesiol 3(2): 1046.

Howell, P., Tennant, I., Augier, R., Gordon-Strachan, G, and Harding Goldson, H. (2013). Physicians' Knowledge Of Cardiopulmonary

Resuscitation Guidelines and Current Certification Status At The University Hospital Of The West Indies, Jamaica. West Indian Med J 2014; 63 (7): Pp 739-743.

Kamus Besar Bahasa Indonesia Online. (2017). Provided On: Http://Kbbi.Kata.Web.Id. On-Line: 04 Januari 2019. 20.00.

Meliono \& Irmayati (2007).MPKT Modul I. Jakarta. Lembaga Penerbitan FEUI. Http://Id.Wikipedia.Urg/Wiki/Pengetahuan. On-Line: 04 Januari 2019. 20.00 .

Monica E. Kleinman, Et All. (2017). American Heart Association Focused Update On Adult Basic Life Support and Cardiopulmonary Resuscitation Quality: An Update To The American Heart Association Guidelines For Cardiopulmonary Resuscitation and Emergency Cardiovascular Care. Https://Www.Ahajournals.Org/Doi/Full/10.1161/CIR.0000000000000539 On-Line: 04 Januari 2019. 20.00. Narayan, D.P.R., Biradar, S. V., Reddy, M. T., \& Sujatha, B. K. (2015) 
154 Jurnal Empathy, Volume 1, No 2, Desember 2020, hlm 96-190

Assessment Of Knowledge And Attitude About Basic Life Support Among Dental Interns and Postgraduate Students In Bangalore City, India. World J Emerg Med 2015;6(2). Pp.118-122.

Notoatmodjo, S. (2003). Promosi Kesehatan dan Ilmu Perilaku. Jakarta : Rineka Cipta 